\title{
Beautiful love of Maeg wife! (IbbeunGaksi!) (801st - 816th)
}

\author{
Hyeonhi Regina Park1, Kunjoo DaegonAndrea Kim², Jiah Anna Kim³, Rosa Kim, Alain Hamon5, Sohwa \\ Therese Kim${ }^{6}$, Sangdeog Augustin $\mathrm{Kim}^{7^{*}}$
}

\author{
${ }^{1}$ Department of Elderly care and welfare, Joongbu University, Kumsan, Republic of Korea (ROK) \\ 2Department of History, Yonsei University, Seoul, ROK \\ ${ }^{3}$ Department d'Expertise economique, Universite de Paris-Est Creteil, Paris, France \\ ${ }^{4}$ Specialite d'Economie politique, Ecole des Hautes Etudes en Sciences Sociales (EHESS), Paris, France \\ 5L'Ecole Internationale Jean-Mermoz, Abidjan, Cote d'Ivoire), \\ ${ }^{6}$ Department of French language and literature, Seoul Women's University, Seoul, ROK \\ ${ }^{7}$ Department of Companion animal and animal resources science, Joongbu University, Kumsan, ROK)
}

\section{*Corresponding Author}

Sangdeog Augustin Kim

\section{Article History}

Received: 05.08.2019

Accepted: 20.08 .2019

Published: 25.08.2019

\begin{abstract}
There was a country whose name was Maeg, and the people of Maeg country used similar language to modern Korean. The people of Tsin(Qin) country, the first unified country in China, used the Korean languages and the people utilized Tcheonzamun as a text for children, and Shang(Historically the second country in China) reorganized the Tsin country. The people's thinking of Shang country has similarity to that of our country, Korea. It is so in the viewpoint of searching for God. It is supposed that the peoples of Shang - Tsin(Qin) - Maeg - Korea were similar in a viewpoint of language. The researchers have considered that a Tcheonzamun poem was composed of 16 letters. This time also Tcheonzamun(The Thousand Character Essay) poem was composed of 16 letters from 801st to 816th characters. And the researchers used two translating methods. The first method is to utilize the meaning of Chinese characters and to translate the poem with 16 letters. And the other method is to utilize Korean pronunciation of the poem. The meaning between the two translating methods were similar. This Tcheonzamun poem seems to be written by a woman of Maeg country. And it shows the 'Beautiful love of Maeg wife'. And it is considered that there is a close relation between ShangTsin(Qin)-Maeg-Korean peoples.
\end{abstract}

Keywords: Beautiful love, IbbeunGaksi, Maeg wife, peoples of Shang-Tsin(Qin)-Maeg-Korea, viewpoint of language, viewpoint of searching for God, woman writer.

\section{INTRODUCTION}

'IbbeunGaksi!' is a dialect of Korean language, and the meaning of 'IbbeunGaksi!' is beautiful wife or sensible wife. Once upon a time there was a country, its name was Maeg [1, 2], and they used similar language to modern Korean [3-5]. The people of Tsin(Qin) country, the first unified country in China, used the Korean languages [6] and the people utilized Tcheonzamun(The Thousand Character Essay) as a text for children [7], and Shang(Historically the second country in China) reorganized the Tsin country [8]. It is supposed that Shang - Tsin - Maeg - Korean they were similar people in a viewpoint of language.

In Shang country, which flourished until around 3000 years ago in the old China, a lot of Chinese characters were found either on turtle surface (carapace) or buffalo bone. And the number of Chinese characters script on the animals body was reported as 3000 [9]. It is possible that the Tcheonzamun(The Thousand Character Essay) poem from 801 st to 816th characters was written by a woman of Maeg country. And it is considered that the time of Tcheonzamun spread into China might be before the era of Confucius (500 B.C.) [3]. The researchers have interests on the origin of Korean people [5], and they found that the letters on Tcheonzamun can be translated on Korean pronunciation [6]. Most

Copyright @ 2019: This is an open-access article distributed under the terms of the Creative Commons Attribution license which permits unrestricted use, distribution, and reproduction in any medium for non commercial use (NonCommercial, or CC-BY-NC) provided the original author and source are credited. 
of the poems of Tcheonzamun were principally concerned on the world of Man; combat, killing the enemy, defeat, and child education [4,5], but this time the theme was different. It shows the small but important controversy between a wife and a husband during common life.

\section{Materials and Methods}

The researchers utilized common Tcheonzamun (The Thousand Character Essay) book in Korea [10]. The researchers have considered that a Tcheonzamun poem was composed of 16 letters [3-5]. This time also Tcheonzamun (The Thousand Character Essay) poem was composed of 16 letters from 801st to 816th characters. And the researchers used two translating methods. The first method is to utilize the meaning of Chinese characters and to translate the poem with 16 letters. And the other method is to utilize Korean pronunciation of the poem.

\section{RESULTS ANd Discussion}

Tcheonzamun (The Thousand Character Essay) was translated simply in Korea [10] and in English(Sturman www.camcc.org). This Tcheonzamun poem seems to be written by a woman of Maeg country. The poem is composed of 16 letters from 801st to 816th characters.

The next is the talking of Augustin and Hyeonhi on 24 May 2017 during their eating of the breakfast.

Augustin: I have written a lot of things about Chinese history, principally on Ha country (historically the first Chinese country) and Shang (or Eun) country (historically the second country in China).

Hyeonhi: Do you want to say that there is a relation between the Chinese history and that of our country, Korea?

Augustin: Yes, it is. I think that both Ha country and Shang (Eun) country have relations with us, Korean people.

Hyeonhi: My Darling, it is raining outdoors.

Augustin: Especially the people's thinking of Shang country has similarity to that of our country. It is so in the viewpoint of searching for God.

Hyeonhi: Please take your meal of breakfast. You must go out early because it is raining.

Augustin: Yes, I will do so. It is very long time ago from now. Shang country existed on the latter period of Neolithic era. By the way, it is said that there were 2000 Chinese character in the period of Shang country. I think it is not true. I think that more than 2000 Chinese characters existed in Shang period.

Hyeonhi: Now get up please! It is time to come to School.

Augustin: Yes. Thank you very much my Darling. You have lived together with me!

Hyeonhi: Of course! See you at night after your work in your University!

Thank you very much! The LORD of us, two persons Hyeonhi and Augustin.

It was on the memo written in the University bus going to the school in the morning of 24 May 2017.

Thank you our LORD! It is the LORD who gives the couple of Augustin and Hyeonhi the ability to translate this poem of Tcheonzamun amen! This poem is consisted of 16 letters from 801st to 816th characters of Tcheonzamun. And the title is 'lbbeunGaksi!' whose meaning is beautiful wife or sensible wife.

The next part is translation through Chinese character of the poem of 16 letters from 801st to 816th characters of Tcheonzamun. The Maeg wife saw that her husband ate solitarily the cold meal in the kitchen. Perhaps after the quarrel with her wife, the Maeg husband did not demand to his wife his meal. Korea and Maeg countries (Maeg is the name of ancient Korea, and the Maeg people might have lived among the west part of present China, the Mongol, the Mandchou, the present Korea[North Korea and South Korea]) have four seasons; therefore if somebody eats cold meal, it is not normal meal but eating something in order to escape his being hungry.

Though it was not clear, the researchers during the translation through Chinese character found that the woman writer has expressed in this poem her status of being wife. And the Maeg wife exposed herself secretly and metaphorically figured herself as 'meal'.

Number, Chinese character in Korean pronunciation, Chinese character, Translation through Chinese character 801-804 Ku Seon Tchan Ban 具膳餐飯 If I want to prepare (具) a good meal for you, my husband, (膳), I must change the bad rice-meal and bad food (飯) into the good quality rice-meal and favorite food (餐). 
805-808 Zeog Gu Tchung Zang 適口充腸 No, it is not right, it is wrong. The appetite (口) comes to me (適) during my eating (充) of the meal (腸).

Supposing that it was not a delicious meal. But during my eating of the meal it becomes more and more tasty if I eat it deliciously.

809-812 Po Eo Paeng Zae 飽(食+夭)烹宰 If I prepare for you the meal with the common materials in my house (宰). I will cook it well for long time with my sincere love (烹), and you can eat it deliciously and sufficiently (飽). You will not take the meal reluctantly, or you will not eat the food in order to escape your hunger (食+夭).

813-816 Ki Yeom Zo Gang 飢厭糟糠 You may abandon as refuse (糟) the good meal (糠) if you wish to die with malnutrition (飢). At first time you eat the bad food (厭). But because of its being untasty, you can not tolerate eating the bad meal. At last you will die with hunger.

The next are found in the Bible (Proverbs, chapter 5 , number shows the sections 15; 18-21). Augustin wrote on 26 September 2017 a brief memo as follows;

"LORD, yesterday I have happened to read these sentences from 'Proverbs', on the time just before I was going to return from University to my home. And my LORD, I have entered yesterday (25 September 2017) this part of the Bible into this article of 'IbbeunGaksi!' Lord of us two people, Hyeonhi and Augustin, we thank you very much!

(15) Be faithful to your own wife and give your love to her alone. (18) So be happy with your wife and find your joy with the woman you married - (19) pretty and graceful as a deer. Let her charms keep you happy; let her surround you with her love. (20) Son, why should you give your love to another woman? Why should you prefer the charms of another man's wife? (21) The LORD sees everything you do. Wherever you go, he is watching.

The next is the interpret of this Tcheonzamun poem through Korean pronunciation.

Number, Chinese character in Korean pronunciation, Chinese character, ((Modified into modern Korean words)) (Pronunciation; its meaning)

801-804 Ku Seon Tchan Ban 具膳餐飯 ((구석 찬밥)) (Ku Seog Tchan Bab; a cold meal in a corner of certain place)

You are my loving and the most precious husband, however, you eat the cold meal in the corner of the kitchen! I am really sorry to see you in this condition!

After the just finish of my undergraduate course in Konkuk University, I(Augustin) continued to live on a small underground room where the instruments for farming experience were conserved. The room was belonged to the 'Laboratory of Grassland science' of 'Department of Feed science' on 'College of Animal husbandry' of the University. When Hyeonhi saw me to eat and to sleep on the inconvenient condition at the autumn of 1981, she seemed to be sorry about me. At the same time, Hyeonhi thought me good about my appearance and the poor condition of me. It was the thing happened around one and half years before our marriage.

Yes, it was the beautiful love of my wife Hyeonhi! Hyeonhi is really IbbeunGaksi (the meaning of this Korean word is 'beautiful wife')!

805-808 Zeog Gu Tchung Zang＼cjkstart適口充腸（(주구장창)) (Zu Gu Zang Tchang; continuously for very long time)

No, it is not right! of course not! I saw that you have eaten solitarily the cold meal, it is not possible for me to see you at this condition. My Darling, I will sincerely prepare for long time your hot meal and good food, take this one! Do not go to other woman! I will prepare your meal. My meal and food for you is tasty, isn't it? My Darling! 
809-812 Po Eo Paeng Zae 飽(食+夭)烹宰 ((포옥 펴서)) (Po Ok Pyeo Seo; boil the meal completely, prepare the food and extend it for eating)

I will make the food and the meal boiled for you, and I will take the food which I have prepared, and I will extend the things on the eating table for you. The meal shall be delicious. Please take the warm food and the hot meal, my Darling, my Husband!

\section{3-816 Ki Yeom Zo Gang 飢厭糟糠（(귀여운 짝아)) (Kwi Yeo Un Zzag A; Oh my Darling, pretty, lovable) \\ Please take the meal! My loving husband! Listen to me please!}

It is the conversation between Augustin and Hyeonhi on the night of 7 February 2017.

Augustin: My Darling! Can a wife say that her husband is 'pretty' or 'lovable'?

Hyeonhi: It is possible. It depends upon its condition. For example, when her husband is younger than her. Jesus our LORD amen!

Some times ago(14 May 2017) Father JeongEop Paul Lee in the Catholic Church of Daejeon Nae-dong told us that "Our life is very important."

"Because our neighbors generally see us on the viewpoint of our common life."

The meaning between the two translating methods were similar. And it shows the 'Beautiful love of Maeg wife'. And it is considered that there is a close relation between Shang-Tsin (Qin)-Maeg-Korean peoples.

\section{ACKNOWLEDGEMENTS}

We thank Mr Ilsoo Joseph Kim and Mrs Bohwa Kim, Mr Yeonghag Park and Mrs Hilye Sarah Kim. We thank Father Jean Blanc who came from France to Republic of Korea of Missions Etrangeres de Paris, who allowed us to read the book of 'Histoire de l'Eglise de Coree'(History of Korean Catholic Church). We thank Father Hifumi Iwazaki who helped us when Augustin was a foreign student in Japan. Father Daiyuu David Ito, Father JungEob Paul Lee, Father Junyoung Andrea Kim, Father JeongHyun Stephanus Han, Father Sangsoon Pio Choi. We thank the students of Department of Companion Animal and Animal Resources Science in Joongbu University. We thank Mrs Tamako Hayashi and Mr Yoshihiro Hayashi, Mrs and Mr Kuromiya, Mrs Francine Tenaillon and Professor Nicolas Tenaillon for their supports during our stay in Japan and in France, and the members of Daejeon Ludovich of Ordo Franciscanus Saecularis (OFS).

\section{Conflict of Interests}

There is not any conflict of interests in this article.

\section{BibLIOGRAPHICAL REFERENCES}

1. Park, H. R., Kim, J. A., Kim, K. D., Kim, J. A., Kim, S. T., Hamon, A., ... \& Kim, S. A. (2017). The son and the daughter of Maeg country, I am very proud of you! with a title I will do my best for my children as if I stood in front of God!:-Translation of the poem on Tcheonzamun (the book of The Thousand Character Essay), from 689th to 704th characters. Journal of Languages and Culture, 8(3), 28-31..

2. Chung, I. B. (2013). Choseonsa Yeonku (Study of Korean History)(Edited by SJ Moon). Korea History Foundation. Seoul, 2, 20-959.

3. Park, H. R., \& Kim, S. A. (2017). Dont be an idiot! Fight! with the apparent title of you must write it in your words as historical records by your own hand: Translation of the poem on Tcheonzamun (the book of The Thousand Character Essay) from 673rd to 688th using Chinese characters and Korean pronunciation. Journal of Languages and Culture, 8(3), 24-27.

4. Park, H. R., Kim, J. A., Kim, K. D., Kim, J. A., Kim, S. T., Hamon, A., .. \& Kim, S. A. (2017). The son and the daughter of Maeg country, I am very proud of you! with a title I will do my best for my children as if I stood in front of 
God!:-Translation of the poem on Tcheonzamun (the book of The Thousand Character Essay), from 689th to 704th characters. Journal of Languages and Culture, 8(3), 28-31.

5. Hyeonhi, R. P., Jieun, A. K., Kunjoo, D. A., Jiah, A. K., Sohwa, T. K., Kim, R., ... \& Sangdeog, A. K. (2017). Ancient Koreans petition to God in Tcheonzamun: The thousand character essay poem (641st to 656th letters). Journal of Languages and Culture, 8(6), 79-84.

6. Nam, J., Won, N., Jin, H., Chung, H., \& Kim, S. (2009). pH-induced aggregation of gold nanoparticles for photothermal cancer therapy. Journal of the American Chemical Society, 131(38), 13639-13645l.

7. Dallet CH (1874). Histoire de l'Eglise de Coree (History of Korean Catholic Church). Victor Palme. Paris. France. pp.11-99.

8. Gernet ,J. (2005). Le Monde chinois. 1. De l'age de bronze au Moyen Age. Armand Colin, Paris. p. 145

9. Tchang, S.S. (1972). Silyong Hanza ZungSazeon(Middle-sized Dictionary of Chinese characters). Kyohagsa Publishing Company. 8-9. (Seoul).

10. Kim, J. J. (2002). HanSeogBong Tcheonzamun. 